\title{
New Modified-Multiwall Carbon Nanotubes Paste Electrode for Electrocatalytic Oxidation and Determination of Hydrazine Using Square Wave Voltammetry
}

\author{
Ali A. ENSAFI*, Mahsa LOTFI, Hassan KARIMI-MALEH \\ Department of Chemistry, Isfahan University of Technology, Isfahan 84156-83111, Iran
}

\begin{abstract}
The application of $p$-aminophenol as a suitable mediator, as a sensitive and selective voltammetric sensor for the determination of hydrazine using square wave voltammetric method were described. The modified multiwall carbon nanotubes paste electrode exhibited a good electrocatalytic activity for the oxidation of hydrazine at $\mathrm{pH}=7.0$. The catalytic oxidation peak currents showed a linear dependence of the peaks current to the hydrazine concentrations in the range of $0.5-175 \mu \mathrm{mol} / \mathrm{L}$ with a correlation coefficient of 0.9975 . The detection limit $(\mathrm{S} / \mathrm{N}=3$ ) was estimated to be $0.3 \mu \mathrm{mol} / \mathrm{L}$ of hydrazine. The relative standard deviations for 0.7 and $5.0 \mu \mathrm{mol} / \mathrm{L}$ hydrazine were 1.7 and $1.1 \%$, respectively. The modified electrode showed good sensitivity and selectivity. The diffusion coefficient $\left(D=9.5 \times 10^{-4} \mathrm{~cm}^{2} / \mathrm{s}\right)$ and the kinetic parameters such as the electron transfer coefficient $(\alpha=0.7)$ of hydrazine at the surface of the modified electrode were determined using electrochemical approaches. The electrode was successfully applied for the determination of hydrazine in real samples with satisfactory results.
\end{abstract}

Key words: hydrazine determination; modified carbon nanotubes paste electrode; electrocatalytic measurement; voltammetry CLC number: O643 Document code: A

Received 30 August 2011. Accepted 30 November 2011.

*Corresponding author.Tel: +98-311-3913269; Fax:+98-311-3912350; E-mail: Ensafi@cc.iut.ac.ir, Ensafi2009@gmail.com English edition available online at Elsevier ScienceDirect (http://www.sciencedirect.com/science/journal/18722067).

Hydrazine is a highly reactive base and reducing agent. Its primary uses are as a high-energy rocket propellant, as a reactant in military fuel cells, in nickel plating, in the polymerization of urethane, for removal of halogens from wastewater, as an oxygen scavenger in boiler feed water to inhibit corrosion, and in photographic development [1]. Hydrazine was historically used as a therapeutic agent in the treatment of tuberculosis, sickle cell anemia, and non-specific chronic illnesses [1]. However, environmental protection agency (EPA) has reported hydrazine and its derivatives as environmental pollutants and the maximum recommended value of hydrazine in effluents is set to $0.0001 \%$ [2]. Because of the great importance of hydrazine, its accurate and economical determination is still a challenging research in analytical chemistry. Several methods have been proposed for the determination of hydrazine including spectrophotometry [3], amperometry [4], potentiometry [5], titrimetry [6], and chemiluminescence [7].

Electrochemical techniques offer the opportunity for portable, economical, sensitive, and rapid methodologies. On other hand, the electrooxidation of hydrazine at carbon electrodes are kinetically slow and are accompanied with large overpotentials. Modification of the electrode surface is an approach to enhance the rate of electron transfer and minimize its overpotential. Several redox mediators such as pyrogallol red [8], various transition metal hexacyanoferrates [9], chlorogenic acid [10], ferrocencarboxylic acid [11], coumestan [12], and metal phthalocyanines [13] have been used to modify the graphite electrodes for hydrazine determination. $p$-Aminophenol has been used as a suitable mediator for the determination of thioguanine [14], pencillamine [15], mercaptopurine [16], cysteine plus tryptophan [17], and cysteamine [18]. The electrocatalytic behavior of $p$-aminophenol for oxidation of organic compounds is depends on the solution $\mathrm{pH}$ and type of the analyte. In continuation of our studies concerning the preparation of chemically modified electrodes [14-20], we decided to evaluate this mediator for the electrooxidation of important inorganic compounds such as hydrazine. Here we describe the use of multiwall carbon nanotubes modified with $p$-aminophenol as sensor for the electrooxidation of hydrazine in aqueous media. We tested the suitability of the modified multiwall carbon nanotubes paste electrode using cyclic voltammetry, double potential step chronoamperometry, square wave voltammetry, and electrochemical impedance spectroscopy. Finally, the modified electrode was found to be a selective, simple, and precise new electrochemical sensor for the determination of hydrazine in real 
samples.

\section{Experimental}

\subsection{Chemicals}

All chemicals used were of analytical reagent grade purchased from Merck (Darmstadt, Germany) unless otherwise stated. Double distilled water was used throughout the experiments. $p$-Aminophenol from Fluka and hydrazine from Merck were used as received.

The hydrazine solution $(0.01 \mathrm{~mol} / \mathrm{L})$ was prepared daily by dissolving $0.05 \mathrm{~g}$ hydrazine in water and the solution was diluted to $100 \mathrm{ml}$ with water in a $100 \mathrm{ml}$ volumetric flask. The solution was kept in a refrigerator at $4{ }^{\circ} \mathrm{C}$ in dark. Further dilution was made with buffer solution.

Phosphate buffer solutions (sodium dihydrogen phosphate and disodum monohydrogen phophate plus sodium hydroxide, $0.1 \mathrm{~mol} / \mathrm{L}$ ) with different $\mathrm{pH}$ values were prepared and used.

High viscosity paraffin $(d=0.88 \mathrm{~kg} / \mathrm{L})$ from Merck was used as the pasting liquid for the preparation of the paste electrodes. Spectrally pure graphite powder (particle size $<50 \mu \mathrm{m})$ from Merck and multiwall carbon nanotubes ( $>90 \%$ MWCNTs basis, $d \times 1=(110-70 \mathrm{~nm}) \times(5-9 \mu \mathrm{m}))$ from Fluka were used as substrates for the preparation of the paste electrodes.

\subsection{Apparatus}

Square wave voltammetry (SWV), cyclic voltammetry (CV), and impedance spectroscopy were performed in an analytical system using an Autolab PGSTAT 12, potentiostat/galvanostat connected to a three-electrode cell, Metrohm Model 663 VA stand, linked with a computer (Pentium IV, $1200 \mathrm{MHz}$ ) and with Autolab software. The system was run on a PC using GPES and FRA 4.9 software packages. For impedance measurements, a frequency range of 100000 to $1.0 \mathrm{~Hz}$ was employed. The AC voltage amplitude of $5 \mathrm{mV}$ with $1 \mathrm{~min}$ equilibrium time was used. The $\mathrm{SWV}$ was recorded with an amplitude potential of $50 \mathrm{mV}$, and frequency of $10 \mathrm{~Hz}$. A conventional three-electrode cell assembly was used which consists of a platinum wire as an auxiliary electrode and an $\mathrm{Ag} / \mathrm{AgCl}\left(\mathrm{KCl}_{\text {sat }}\right)$ electrode as a reference electrode. The working electrode was either an unmodified multiwall carbon nanotubes paste electrode (CNPE) or $p$-aminophenol-modified multiwall carbon nanotubes paste electrode ( $p$-APMWCNTPE).

The prepared carbon nanotubes electrodes with and without the modifier were characterized by scanning electron microscopy (SEM, XLC Philips).

A pH-meter (Corning, Model 140) with a double junction glass electrode was used to check the $\mathrm{pH}$ levels of the solutions.

\subsection{Preparation of the modified electrode}

p-Aminophenol $(1.0 \mathrm{mg}$ ) was hand-mixed with $89 \mathrm{mg}$ of graphite powder and multiwall carbon nanotubes $(10 \mathrm{mg})$ in a mortar and pestle. Using a syringe, $0.88 \mathrm{~g}$ of paraffin was added to the mixture and mixed well for 40 min until a uniformly wetted paste was obtained. The paste was then packed into a glass tube. A copper wire was pushed down the glass tube into the back of the mixture to make electrical contact. When necessary, a new surface was obtained by pushing an excess of the paste out of the tube and polishing it on a weighing paper. The unmodified carbon paste electrode (CPE) was prepared in the same way without adding $p$-aminophenol and carbon nanotubes to the mixture and used for comparison purposes.

\subsection{Recommended procedure}

Without any pre-treatment of the sample, an accurate volume of the water samples were subjected directly for voltammetric measurement of hydrazine as in recommended procedure.

Before each measurement, the modified-multiwall carbon nanotubes paste electrode was polished with a white and clean filter paper. To prepare a blank solution, $10 \mathrm{ml}$ of the buffer solution ( $\mathrm{PBS}, \mathrm{pH}=7.0$ ) was transferred into the electrochemical cell. The initial and final potentials were adjusted to -0.10 and $+0.25 \mathrm{~V}$ vs $\mathrm{Ag} / \mathrm{AgCl}$, respectively. The SWV was recorded with an amplitude potential of 50 $\mathrm{mV}$, and a frequency of $10 \mathrm{~Hz}$ to give the blank signal and labeled as $I_{\mathrm{pb}}$. Then, different amounts of hydrazine were added to the cell using a micropipette. The SWVs were recorded again (similar to the above procedure) to get the analytical signals $\left(I_{\mathrm{ps}}\right)$. Calibration curve was constructed by plotting the net catalytic peak currents vs the hydrazine concentrations.

\section{Results and discussion}

\subsection{SEM characterization of $p$-APMWCNTPE}

The surface morphology of $p$-APMWCNTPE was examined using scanning electron microscope (SEM). Figure 1(a) shows the presence of $p$-aminophenol in the electrode matrixes with graphite layer and multiwall carbon nanotubes branch. Note that no mediator particle is shown at the unmodified carbon nanotubes paste electrode (Fig. 1(b)).

\subsection{Electrochemical study}



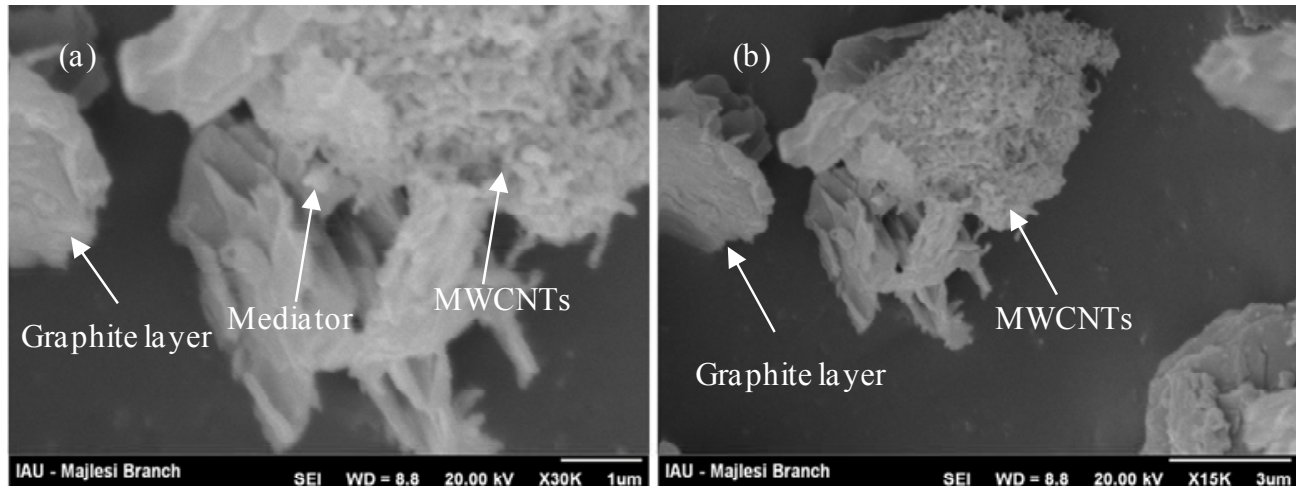

Fig. 1. SEM images of $p$-APMWCNTPE (a) and unmodified CNTPE (b).

The electrochemical property of the modified electrode was studied by $\mathrm{CV}$ in the buffer solution $(\mathrm{pH}=7.0)$. Figure 2 (inset) shows the cyclic voltammograms of the electrode at various scan rates $(v=2.0-300 \mathrm{mV} / \mathrm{s})$. The experimental results showed well-defined and reproducible anodic and cathodic peaks related to $p$ - $\mathrm{AP}_{(\mathrm{Red})} / p-\mathrm{AP}_{(\mathrm{Ox})}$ redox couple with quasi-reversible behavior, with peak separation potential of $\Delta E_{\mathrm{p}}=120 \mathrm{mV}\left(\Delta E_{\mathrm{p}}=E_{\mathrm{pa}}-E_{\mathrm{pc}}\right)$. These CVs were used to examine the variation of the peak currents versus the potential scan rates. The plot of the peak current was depend linearly on $v^{1 / 2}$ with a correlation coefficient of 0.9967 at the all scan rates (Fig. 2(b)). This behavior indicates that the nature of redox process is diffusion controlled [16].

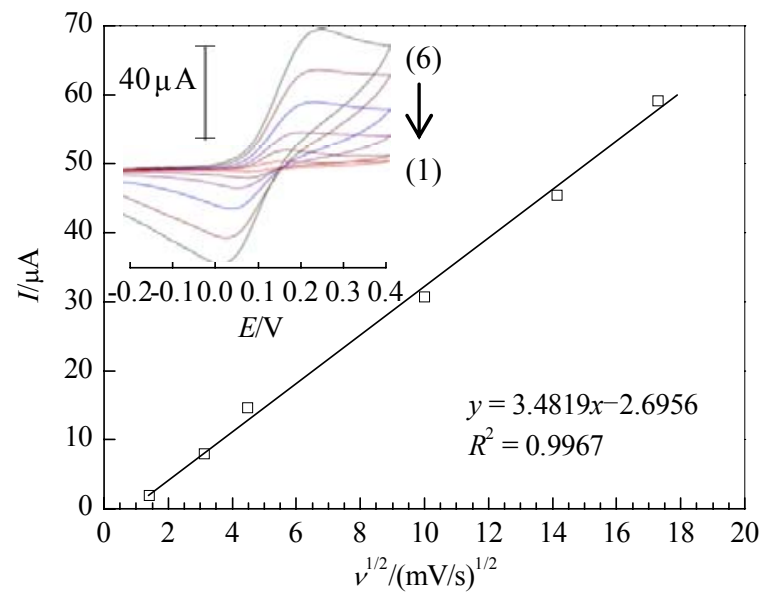

Fig. 2. Plot of $I_{\mathrm{pa}}$ versus $v^{1 / 2}$ for the oxidation of $p$-APMWCNTPE. Inset: cyclic voltammograms at scan rates of 2 (1), 10 (2), 20 (3), 100

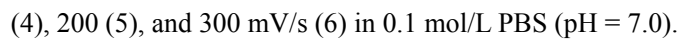

Figure 3 depicts the cyclic voltammetric responses from the electrochemical oxidation of $170 \mu \mathrm{mol} / \mathrm{L}$ hydrazine. As can be seen from Fig. 3, the anodic peak potential for the oxidation of hydrazine at $p$-APMWCNTPE and at $p$-APMCPE was about $200 \mathrm{mV}$, while at CNTPE and at unmodified-CPE were about 784 and $830 \mathrm{mV}$, respectively. These results demonstrate that the best electrocatalytic effect for hydrazine oxidation was observed at

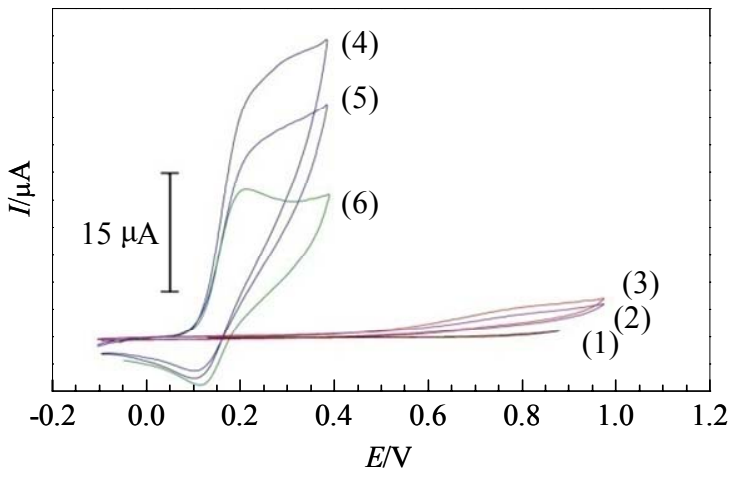

Fig. 3. $\mathrm{CVs}$ of $0.1 \mathrm{~mol} / \mathrm{L} \mathrm{PBS}(\mathrm{pH}=7.0)$ at a scan rate of $20 \mathrm{mV} / \mathrm{s}$. (1) In the absence of $170 \mu \mathrm{mol} / \mathrm{L}$ hydrazine at CPE; (2) In the presence of $170 \mu \mathrm{mol} / \mathrm{L}$ hydrazine at CPE; (3) In the presence of $170 \mu \mathrm{mol} / \mathrm{L}$ hydrazine at CNTPE; (4) In the presence of $170 \mu \mathrm{mol} / \mathrm{L}$ hydrazine at $p$-APMWCNTPE; (5) In the presence of $170 \mu \mathrm{mol} / \mathrm{L}$ hydrazine at p-APMCPE; (6) With the mediator.

$p$-APMWCNTPE. Also, when we compared the oxidation of hydrazine at $p$-APMCPE vs $p$-APMWCNTPE, there was a dramatic enhancement of the anodic peak current at $p$-APMWCNTPE relative to the value obtained at $p$-APMCPE. In other words, the obtained data clearly showed that the combination of carbon nanotubes and the mediator definitely improve the characteristics of hydrazine oxidation. $p$-APMWCNTPE in $0.1 \mathrm{~mol} / \mathrm{L}$ phosphate buffer $(\mathrm{pH}=7.0)$ in the absence of hydrazine exhibited a well-behaved redox reaction.

Upon the addition of $170 \mu \mathrm{mol} / \mathrm{L}$ hydrazine, the anodic peak current of the mediator was significantly increased, while the corresponding cathodic peak decreased in the reverse scan of the potential. This decrease in cathodic peak depends on the hydrazine concentration and also on the scan rate. This behavior is typical of that expected for electrocatalysis at chemically modified electrodes (scheme 1) $[16,17]$.

\section{3 pH optimization}

The electrochemical behavior of $p$-APMWCNTPE and 


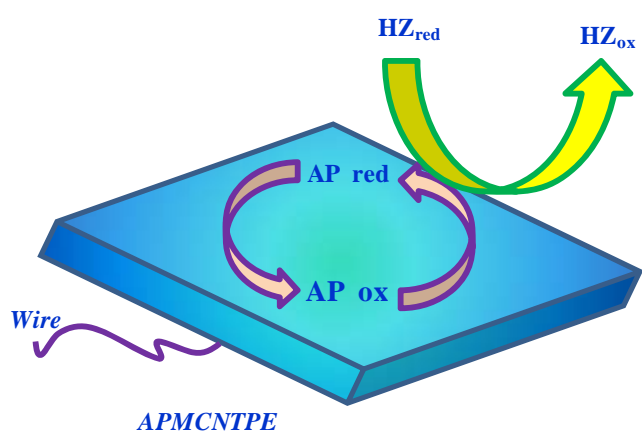

Scheme 1. Electrocatalytic mechanism of the oxidation of hydrazine at $p$-APMWCNTPE surface.

hydrazine is dependent on the solution $\mathrm{pH}$. The formal potential of hydrazine and $p$-aminophenol is shifted to more positive values by increasing the solution $\mathrm{pH}$. Thus, the thermodynamic driving force for the catalysis will vary with $\mathrm{pH}$, making the peak currents and the shapes of the CVs change at different $\mathrm{pH}$ values. Figure 4 shows the plot of peak current vs $\mathrm{pH}$. As can be seen, the results confirm that $\mathrm{pH}=7.0$ is suitable for the electrocatalytic oxidation of hydrazine at the surface of $p$-APMWCNTPE.

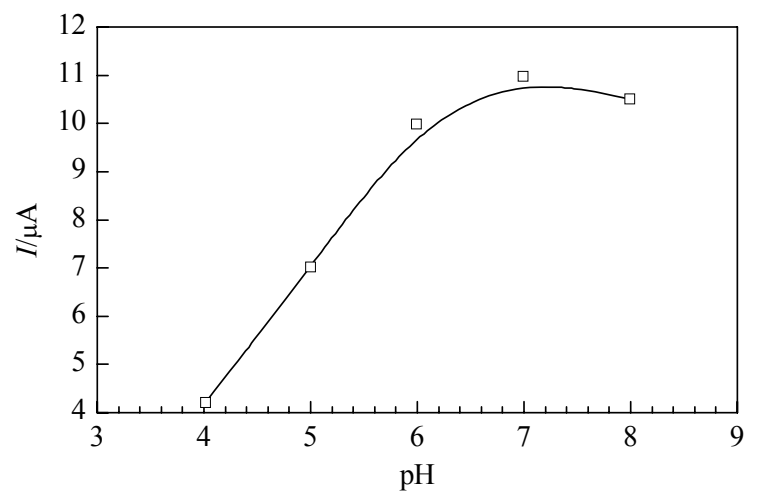

Fig. 4. Net current-pH curve for electrooxidation of $170 \mu \mathrm{mol} / \mathrm{L}$ hydrazine at $p$-APMWCNTPE with a scan rate of $20 \mathrm{mV} / \mathrm{s}$.

\subsection{Scan rate study}

Figure 5 (inset) shows the voltammetric behavior of $p$-APMWCNTPE in a solution containing $170 \mu \mathrm{mol} / \mathrm{L}$ hydrazine $(\mathrm{pH}=7.0)$ at scan rates ranging from $2-20 \mathrm{mV} / \mathrm{s}$. A linear variation of the peak current with the square root of scan rate $\left(v^{1 / 2}\right)\left(R^{2}=0.9958\right)$ was observed (Fig. 5). This result clearly shows a diffusion-controlled electro-oxidative process.

Figure 6 (inset) shows the CV of $p$-APMWCNTPE in 0.1 $\mathrm{mol} / \mathrm{L}$ phosphate buffer $(\mathrm{pH}=7.0)$ containing $170 \mu \mathrm{mol} / \mathrm{L}$ hydrazine at a scan rate of $20 \mathrm{mV} / \mathrm{s}$. The points that show the rising part of the voltammogram, which is known as Tafel region, is affected by electron transfer kinetics between hydrazine and $p$-APMWCNTPE, assuming the de-

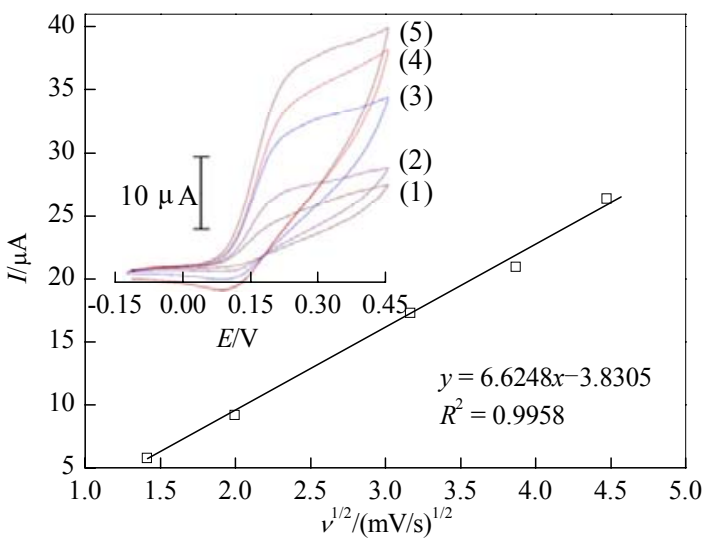

Fig. 5. Cyclic voltammograms of $170 \mu \mathrm{mol} / \mathrm{L}$ hydrazine at various scan rates in $0.1 \mathrm{~mol} / \mathrm{L}$ PBS $(\mathrm{pH}=7.0)$ and plot of $I_{\mathrm{pa}} \mathrm{vs} v^{1 / 2}$ for the oxidation of hydrazine at p-APMWCNTPE. (1) 3.0 ; (2) 5.0 ; (3) 10.0; (4) 15.0 ; (5) $20 \mathrm{mV} / \mathrm{s}$.

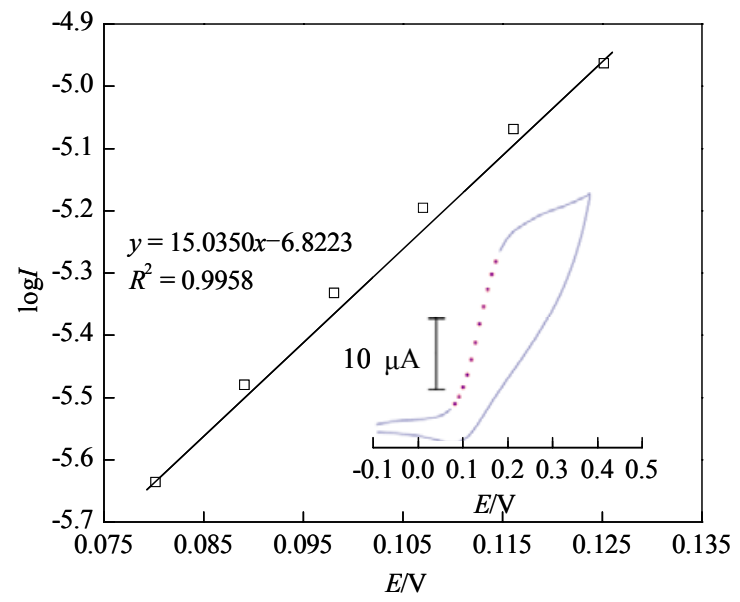

Fig. 6. Tafel plot for $p$-APMWCNTPE in $0.1 \mathrm{~mol} / \mathrm{L}$ PBS $(\mathrm{pH}=7.0)$ with a scan rate of $20 \mathrm{mV} / \mathrm{s}$ in the presence of $170 \mu \mathrm{mol} / \mathrm{L}$ hydrazine.

protonation of hydrazine at a sufficiently fast step.

In the evaluation of kinetic parameters, the Tafel plots were drawn (Fig. 6), derived from points of the Tafel region of the CV (Fig. 6, inset). The results of polarization studies for electrooxidation of hydrazine at $p$-APMWCNTPE showed the average Tafel slope of $15.03 \mathrm{~V}^{-1}$. Using the Tafel equation $(n(1-\alpha) F / 2.3 R T)$, we obtained average charge transfer coefficient $(\alpha)$ of 0.7 . In addition, the value of $\alpha n_{\alpha}$ ( $n_{\alpha}$ is the number of electrons involved in the rate determining step) was calculated for the oxidation of hydrazine at $\mathrm{pH}$ $=7.0$ for both the modified and unmodified carbon nanotubes paste electrodes, using the following equation [19]:

$$
\alpha n_{\alpha}=0.048 /\left(E_{\mathrm{P}}-E_{\mathrm{P} / 2}\right)
$$

where $E_{\mathrm{P} / 2}$ is the potential corresponding to $I_{\mathrm{P} / 2}$. The values for $\alpha n_{\alpha}$ were found to be 0.7 and 0.2 at the surface of $p$-APMWCNTPE and the unmodified carbon nanotubes paste electrode, respectively. These values show that the overpotential of hydrazine oxidation is reduced at the sur- 
face of $p$-APMWCNTPE, and also the rate of electron transfer process is greatly enhanced.

\subsection{Chronoamperometric study}

Double-step potential chronoamperometry was employed to investigate the electrochemical processes of p-APMWCNTPE (Fig. 7(a)). The diffusion coefficient, D, of hydrazine in solution was determined using chronoamperometric studies. The experimental plots of $I$ vs $\mathrm{t}^{-1 / 2}$ with the best fits for different concentrations of hydrazine were showed in Fig. 7(b). The slopes of the resulting straight lines were then plotted versus hydrazine concentrations. From whose slope, we calculated a diffusion coefficient $(D$ $=9.5 \times 10^{-4} \mathrm{~cm}^{2} / \mathrm{s}$ ) for hydrazine using the Cottrell equation:

$$
I=n \mathrm{~F} A D^{1 / 2} C_{\mathrm{b}} \pi^{-1 / 2} t^{-1 / 2}
$$

The rate constant for the chemical reaction between hydrazine and redox sites in the $p$-APMWCNTPE, $k_{\mathrm{h}}$, can be evaluated by chronoamperometry according to the method of Galus [22]:

$$
I_{\mathrm{C}} / I_{\mathrm{L}}=\pi^{1 / 2}\left(k C_{\mathrm{b}} t\right)^{1 / 2}
$$

Based on the slope of the $I_{\mathrm{C}} / I_{\mathrm{L}}$ plot vs $t^{1 / 2}$ plots (Fig. 7(c)), we calculated $k_{\mathrm{h}}$ as $4.93 \times 10^{3} \mathrm{~mol} /(\mathrm{L} \cdot \mathrm{s})$. Figure $7(\mathrm{~d})$ shows the double-potential step chronocolougrams for

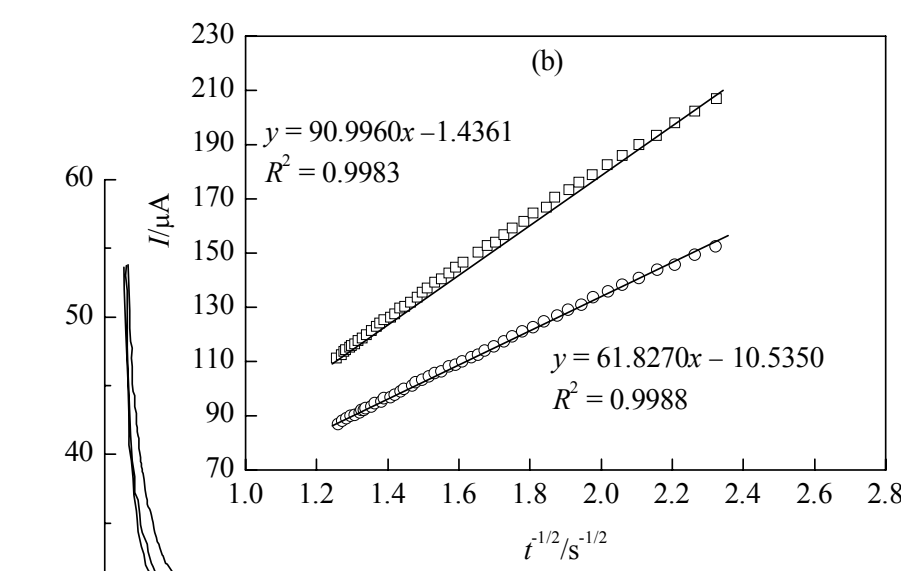

(a)

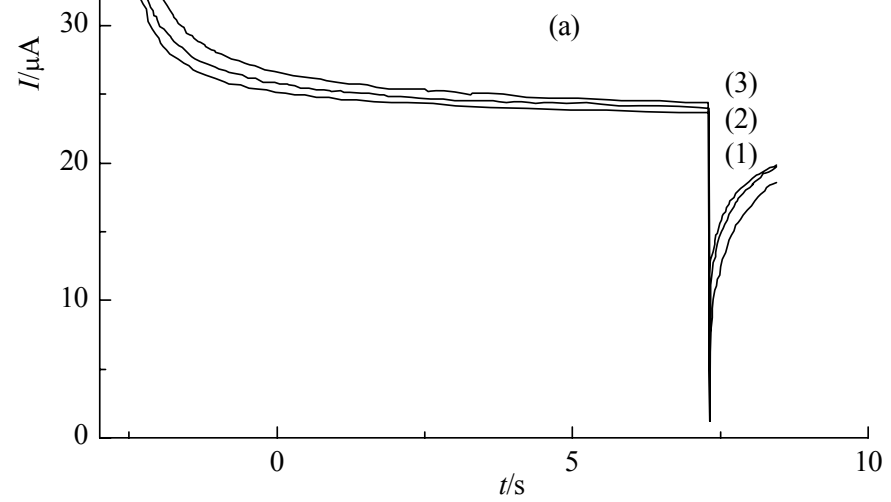

$p$-APMWCNTPE in the absence and presence of different amounts of hydrazine. However, in the presence of hydrazine, the charge value associated with the forward chronocoloumetry was significantly higher than that observed for backward chronocoloumetry. This behavior is typically expected for electrocatalysis at chemically modified electrodes [23].

\subsection{Electrochemical impedance spectroscopic studies}

Figure 8 presents Nyquist diagrams of the imaginary impedance $\left(Z_{\mathrm{im}}\right)$ vs the real impedance $\left(Z_{\mathrm{re}}\right)$ of the electrochemical impedance spectroscopy (EIS) obtained at the modified electrode, recorded at $0.170 \mathrm{~V}$ dc-offset in the absence and in the presence of $600 \mu \mathrm{mol} / \mathrm{L}$ hydrazine in 0.1 $\mathrm{mol} / \mathrm{L}$ PBS $(\mathrm{pH}=7.0)$, respectively. In the absence of hydrazine, the Nyquist diagram comprises a depressed semicircle at high frequencies which may be related to the combination of charge transfer resistance of $p$-AP electrooxidation and the double-layer capacitance, followed by a straight line with a slope of nearly $45^{\circ}$. The latter is due to the occurrence of mass transport process via diffusion. In the presence of hydrazine, the diameter of the semicircle decreases, confirming the electrocatalytic capability of the mentioned electrocatalyst for the oxidation of hydrazine. This is due to
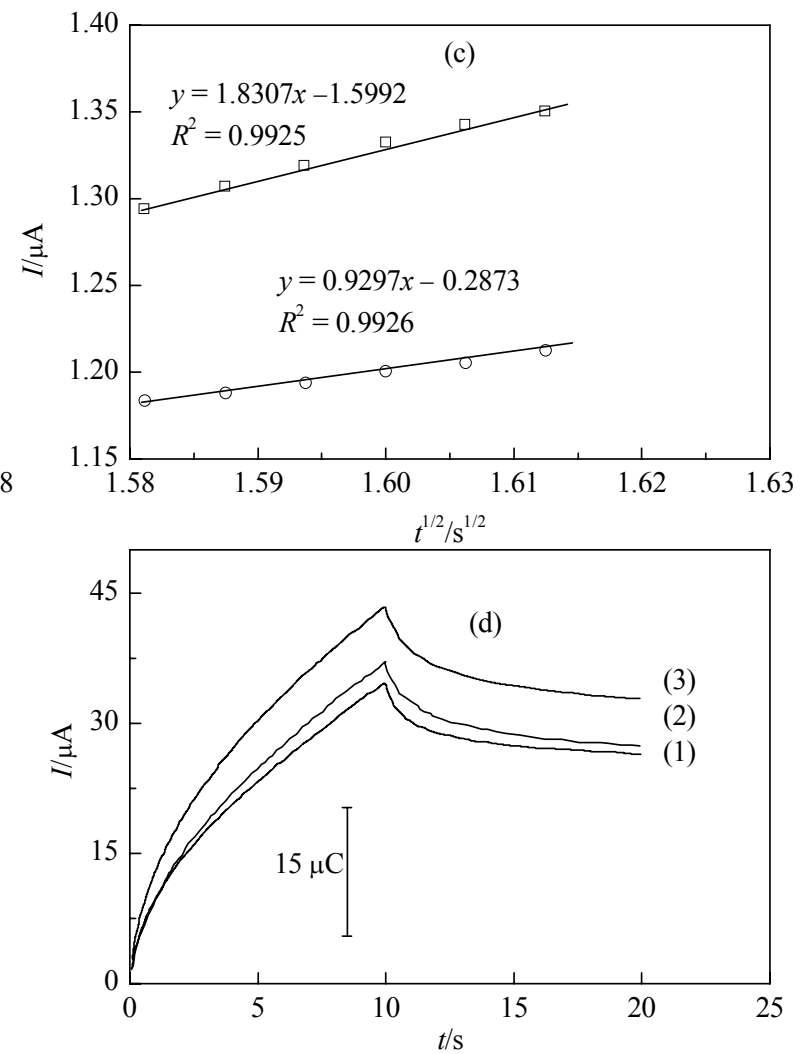

Fig. 7. Chronoamperograms obtained at $p$-APMWCNTPE in the absence (1) and in the presence of $100 \mu \mathrm{mol} / \mathrm{L}$ hydrazine at $\mathrm{pH}=7.0(2)$, and 150 $\mu \mathrm{mol} / \mathrm{L}$ hydrazine at $\mathrm{pH}=7.0$ (3) (a); Cottrell's plot for the data from the chronoamperograms (b); dependence of $I_{\mathrm{c}} / I_{\mathrm{L}}$ on the $t^{1 / 2}$ derived from the chronoamperogram data (c); The charge-time curves: (1) for curve (a)-(1), (2) for curve (a)-(2), and (3) for curve (a)-(3) (d). 


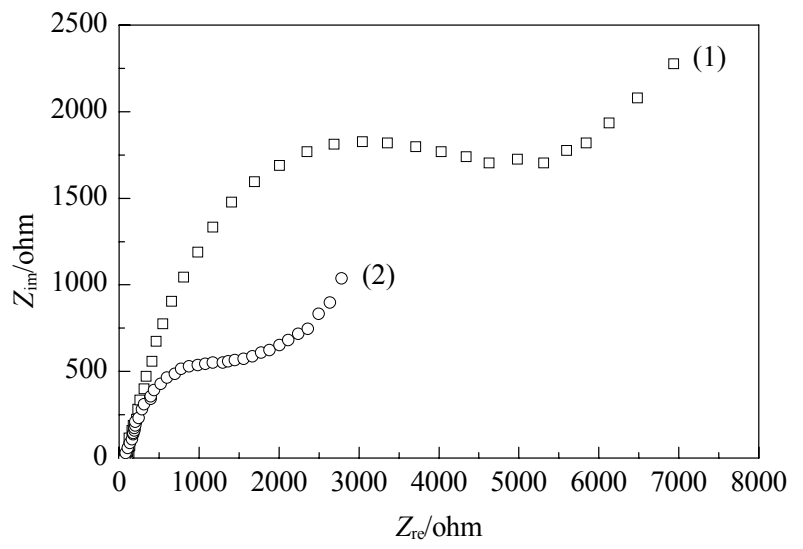

Fig. 8. Nyquist diagrams of $p$-APMWCNTPE in the absence (1) and in the presence of $600 \mu \mathrm{mol} / \mathrm{L}$ hydrazine (2) in $0.1 \mathrm{~mol} / \mathrm{L} \mathrm{PBS}(\mathrm{pH}$ 7.0).

the instant chemical reaction of hydrazine with the high-valence (oxidation form) $p$-AP species. The catalytic oxidation of hydrazine that occurred via the participation of oxidized form of $p$-AP species virtually caused an increase in the surface concentration of low valence species of the electrocatalyst, and the charge transfer resistance is declined, depending on the concentration of hydrazine in the solution.

\subsection{Dynamic range and limit of detection}

In view of industrial and environmental importance of hydrazine determination at low levels, electroanalytical techniques have been employed for its determination. However, in most of the methods reported so far, in order to reach good sensitivity modified electrodes have been used [24]. Here we tried to determine low levels of hydrazine using $p$-AP modified electrode, $p$-APMWCNTPE. For this purpose, square wave voltammetry (with amplitude potential of $50 \mathrm{mV}$, and frequency of $10 \mathrm{~Hz}$ ) was used to determine the concentration of hydrazine. The SW voltammograms clearly showed a linear dynamic range that the plot of the peak current vs hydrazine concentration is linear for 0.5 $-175.0 \mu \mathrm{mol} / \mathrm{L}$ of hydrazine, with a regression equation of $\left.\Delta I_{\mathrm{p}}(\mu \mathrm{A})=(0.4177 \pm 0.0134) C_{\mathrm{HZ}}+1.8286 \pm 0.4211\right)\left(R^{2}=\right.$ $0.9979, n=10)$, where $C_{\mathrm{HZ}}$ is $\mu \mathrm{mol} / \mathrm{L}$ concentration of hydrazine and $\Delta I_{\mathrm{p}}$ is the net peak current. A typical SWV is shown in Fig. 9.

The detection limit was determined as $0.3 \mu \mathrm{mol} / \mathrm{L}$ hydrazine according to the definition of $Y_{\mathrm{LOD}}=Y_{\mathrm{B}}+3 \sigma$.

To check the reproducibility and stability of the modified electrode for hydrazine analysis, the rate of loss of electrochemical activity for the electrode was investigated by measuring any decrease in the anodic charge, $q \mathrm{a}$, in consecutive potential scan cycles. The results showed a de-

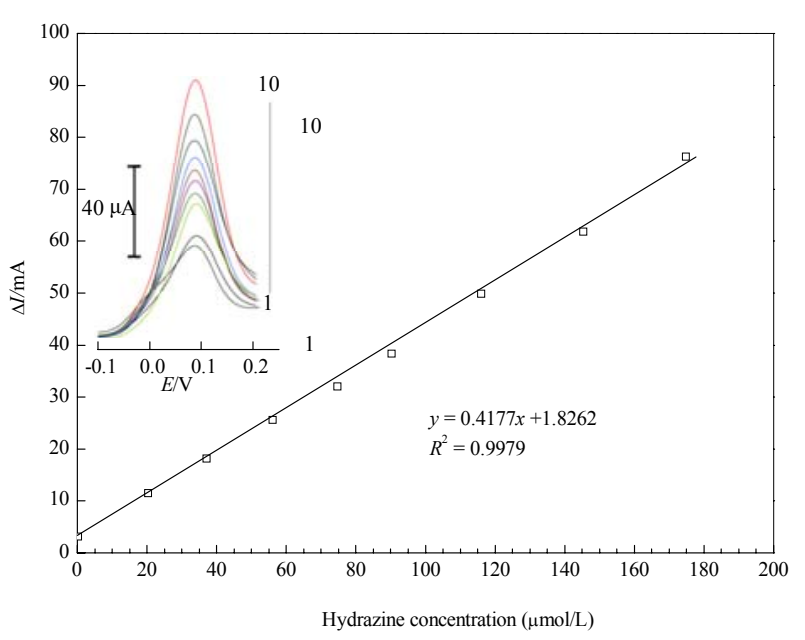

Fig. 9. A typical SWV of different concentration of hydrazine.

crease in the anodic and cathodic peak currents of $p$-AP/ $p$-AP couple after twenty cycles without any change in the half-wave potential, $E_{1 / 2}$. This means that the electrochemical activity of $p$-APMCNTPE during successive scans is reduced. This is due to the dissolving of $p$-aminophenol at the surface of the electrode into the aqueous solution. Therefore, the surface regeneration of $p$-APMCNTPE before each experiment is necessary, using a new white filter paper.

The reproducibility and stability of $p$-APMWCNTPE was investigated using cyclic voltammetric measurements of 0.7 and $5.0 \mu \mathrm{mol} / \mathrm{L}$ hydrazine. The relative standard deviation (RSD\%) for ten successive assays of hydrazine was 1.7 and $1.1 \%$. When four different electrodes were used, the RSD $\%$ for five measurements of $20 \mu \mathrm{mol} / \mathrm{L}$ hydrazine was $2.9 \%$. When the modified electrode was stored in the laboratory, the response of the modified electrode retained $93 \%$ of its initial response value after a week and 90\% after $25 \mathrm{~d}$. These results indicate that $p$-APMWCNTPE has a good stability and reproducibility. Although $p$-aminophenol has lower solubility in water solution, we exited modified electrode after each experiment and changed the solution after some tests.

\subsection{Real sample and interference study}

The influence of various substances as potential interference compounds on the determination of hydrazine was studied under the optimum conditions with $5.0 \mu \mathrm{mol} / \mathrm{L}$ hydrazine at $\mathrm{pH}=7.0$. The tolerance limit was defined as the maximum concentration of the interfering substance that caused an error less than 5\% for determination of hydrazine. The results are given in Table 1, which shows the peak current of hydrazine is not significantly affected by all conventional cations, anions, and organic substances. 
Table 1 Interference study for the determination of $5.0 \mu \mathrm{mol} / \mathrm{L} \mathrm{HZ}$ under the optimized conditions

\begin{tabular}{lc}
\hline Species & $\begin{array}{c}\text { Tolerante limit } \\
\left(W_{\text {Substance }} / W_{\mathrm{GSH}}\right)\end{array}$ \\
\hline $\mathrm{Li}^{+}, \mathrm{ClO}_{4}^{-}, \mathrm{NO}_{3}^{-}, \mathrm{Br}^{-}, \mathrm{Ca}^{2+}, \mathrm{Mg}^{2+}, \mathrm{SO}_{4}^{2-}, \mathrm{CN}^{-}$, & 800 \\
$\mathrm{Ag}^{+}$ & \\
Glucose, Sucrose, Fructose, Lactose, Sulfide & 600 \\
Phenol & 500 \\
Hydrogen peroxide & 100 \\
Hydroxylamine & 1 \\
\hline
\end{tabular}

*After removal with $1.0 \mathrm{mmol} / \mathrm{L} \mathrm{Zn}(\mathrm{II})$.

In order to demonstrate the catalytic oxidation of hydrazine in a real sample, we examined the ability of the modified electrode in determining hydrazine in water samples using SWV.

The determination of hydrazine in real samples was carried out by standard addition method for presentation of any matrix effect. The results obtained are given in Table 2.

Table 2 Determination of hydrazine in water samples

\begin{tabular}{|c|c|c|c|}
\hline Sample & $\begin{array}{c}\text { Hydrazine added } \\
(\mu \mathrm{mol} / \mathrm{L})\end{array}$ & $\begin{array}{l}\text { Hydrazine found } \\
(\mu \mathrm{mol} / \mathrm{L})^{\mathrm{b}}\end{array}$ & $\begin{array}{c}\text { Recovery } \\
(\%)\end{array}$ \\
\hline \multirow[t]{4}{*}{ Tap water } & - & $<$ Detection limit & - \\
\hline & 10.0 & $9.4 \pm 0.4$ & 94.0 \\
\hline & 60.0 & $55.3 \pm 1.6$ & 92.1 \\
\hline & 120.0 & $113.0 \pm 5.6$ & 94.1 \\
\hline \multirow[t]{3}{*}{ River water } & - & $<$ Detection limit & - \\
\hline & 30.0 & $28.4 \pm 0.8$ & 94.6 \\
\hline & 100.0 & $101.1 \pm 3.1$ & 100.1 \\
\hline \multirow[t]{4}{*}{ Boiler water } & - & $<$ Detection limit & - \\
\hline & 50 & $49.1 \pm 3.8$ & 92.2 \\
\hline & 70 & $68.3 \pm 6.5$ & 97.6 \\
\hline & 150 & $144.1 \pm 10.0$ & 96.1 \\
\hline \multirow[t]{3}{*}{ Waste water } & - & $<$ Detection limit & - \\
\hline & 30.0 & $30.9 \pm 3.5$ & 103.0 \\
\hline & 110.0 & $110.0 \pm 10.2$ & 100.0 \\
\hline \multirow[t]{3}{*}{ Well water } & - & $<$ Detection limit & - \\
\hline & 40.0 & $39.2 \pm 2.1$ & 98.0 \\
\hline & 150.0 & $147.0 \pm 2.0$ & 98.0 \\
\hline
\end{tabular}

\section{Conclusions}

This work demonstrates the construction of a chemically modified carbon nanotubes paste electrode by incorporating of $p$-aminophenol to multiwall carbon nanotubes as a suitable electrochemical sensor for hydrazine determination at trace levels. The new voltammetric method for the determination of hydrazine is very rapid (less than 1 min per sample solution), reproducible, selective and sensitive, and can be used for real sample analysis. The results showed that the oxidation of hydrazine is catalyzed at $\mathrm{pH} 7.0$, whereas the peak potential of hydrazine is shifted by $630 \mathrm{mV}$ to a less positive potential at the surface of $p$-APMWCNTPE. In addition, the kinetic parameters of the system have been calculated from the experimental results.

\section{Acknowledgment}

The authors express their appreciation to the Isfahan University of Technology Research Councils and Center of Excellence in Sensors and Green Chemistry for financial support of this work.

\section{References}

1 Von Burg R, Stout T. J Appl Toxicol, 1991, 11: 447

2 Amlathe S, Gupta V K. Analyst, 1988, 113: 1481

3 Safavi A, Abbasitabar F, Nezhad M R H. Chem Anal (Warsaw), 2007, 52: 835

4 Jayasri D, Narayanan S S. J Hazard Mater, 2007, 144: 348

5 Mo J W, Ogorevc B, Zhang X, Pihlar B. Electroanalysis, 2000, 12: 48

6 Budkuley J S. Mikrochim Acta, 1992, 108: 103

7 Safavi A, Karimi M A. Talanta, 2002, 58: 785

8 Ensafi A A, Mirmomtaz E. J Electroanal Chem, 2005, 583: 176

9 Narayanan S S, Scholz F. Electroanalysis, 1999, 11: 465

10 Golabi S M, Zare H R. J Electroanal Chem, 1999, 465: 168

11 Khalilzadeh M A, Karimi-Maleh H. Anal Lett, 2010, 43: 186

12 Zare H R, Nasirizadeh N. Electroanalysis, 2006, 18: 507

13 Ozoemena K I, Nyokong T. Talanta, 2005, 67: 162

14 Mirmomtaz E, Ensafi A A, Karimi-Maleh H. Electroanalysis, 2008, 20: 1973

15 Ensafi A A, Khoddami E, Rezaei B, Karimi-Maleh H. Colloids Surf B, 2010, 81: 42

16 Ensafi A A, Karimi-Maleh H. Drug Testing Anal, 2011, DOI: $10.1002 /$ dta.286, in press

17 Ensafi A A, Dadkhah-Tehrani S, Karimi-Maleh H. Anal Sci, 2011, 27: 409

18 Ensafi A A, Karimi-Maleh H. Electroanalysis, 2010, 22: 2558

19 Ensafi A A, Karimi-Maleh H. J Electronal Chem, 2010, 640: 75

20 Karimi-Maleh H, Ensafi A A, Allafchian A R. J Solid State Electrochem, 2010, 14: 9

21 Karimi-Maleh H, Ensafi A A, Ensafi H R. J Braz Chem Soc, 2009, 20: 880

22 Galus Z. Fundumentals of Electrochemical Analysis. New York: Ellis Horwood, 1976

23 Zhao G, Yin Z, Zhang L, Wei X. Electrochem Commun, 2005, 7: 256

24 Ledesma-García J, Manríquez J, Gutiérrez-Granados S, Godínez L A. Electroanalysis, 2003, 15: 659 